\title{
PENDAYAGUNAAN DANA ZIS UNTUK OPERASIONAL AMBULANCE GRATIS DI BAZNAS REMBANG
}

\author{
Nita Sari \\ Peneliti BAZNAS Rembang \\ e-mail: nitasari914@gmail.com
}

\begin{abstract}
The purpose of this study is to find out how the utilization of zakat, infaq and alms in BAZNAS Rembang for free ambulance operation and to know the obstacles and solutions in the implementation of free ambulance operational program in BAZNAS Rembang. This research uses qualitative method described descriptively with field research approach (field research). The results show that ZIS funds in BAZNAS Rembang are empowered through the program of orphan and poor benefit, the development of Islam, educational scholarship, rehap house unfit for habitation, revolving capital and ambulance and its operation for free. The utilization of ZIS fund for free ambulance operation in BAZNAS Rembang includes driver, fuel, oil, toll road cost, car wash, replacement of spare parts, renewal STNK, service, and repair cost in case of accident. Constraints and solutions in the implementation of the free ambulance operational program in BAZNAS Rembang is the uneven distribution of ambulance cars, the solution that must be done is to increase fundraising of ZIS funds to increase the number of ambulances.
\end{abstract}




\section{Nita Sari}

Keywords: ZIS Utilization, Free Ambulance Operations, BAZNAS.

\section{Pendahuluan}

Setiap muslim mengetahui bahwa zakat adalah salah satu rukun Islam. Zakat merupakan rukun Islam yang mengandung nilai kemasyarakatan (Arfawie, 2005: 5). Zakat juga merupakan sebuah ibadah yang berkaitan dengan harta benda, bernilai ibadah dan juga berdimensi sosial ekonomi. Zakat secara bahasa bermakna mensucikan, tumbuh atau berkembang (Wibisono, 2015: 1). Selain zakat, Islam juga mensyariatkan infaq dan sedekah. Infaq berasal dari kata anfaqa yang berarti mengeluarkan, membelanjakan (harta atau uang) (Arifin, 2011: 173). Adapun infaq merupakan amal ibadah kepada Allah dan amal sosial kemasyarakatan serta kemanusiaan dalam wujud menyerahkan sebagian harta untuk diberikan kepada seseorang ataupun lembaga yang mengelola dana infaq. Sedangkan sedekah adalah memberikan harta atau nilainya atau manfaatnya kepada yang berhak atau patut diberi, karena perintah Allah yang merupakan ibadah sekaligus merupakan amal sosial kemasyarakatan dan kemanusiaan (Arfawie, 2005: 18-20).

Tentang pendayagunaan zakat, infaq, dan sedekah perlu diingat bahwa zakat itu mempunyai dua fungsi utama. Pertama adalah untuk membersihkan harta benda dan jiwa manusia Kedua, zakat, infaq, dan sedekah itu juga berfungsi sebagai dana masyarakat yang dapat dimanfaatkan untuk kepentingan sosial guna mengurangi kemiskinan (Daud Ali, 1988: 61-62).

BAZNAS merupakan lembaga pengelola zakat yang dibentuk oleh pemerintah. Kepengurusan Badan Amil Zakat terdiri dari masyarakat dan unsur pemerintah yang memenuhi persyaratan tertentu, antara lain memiliki sifat amanah, adil, professional, dan berintegritas tinggi (Depag 


\section{Pendayagunaan Dana ZIS untuk Operasional ...}

RI, 2006: 14-15). BAZNAS Rembang telah melakukan berbagai kegiatan termasuk didalamnya yaitu pendayagunaan ZIS. Dalam pendayagunaan ZIS, BAZNAS Rembang mempunyai program-program yang telah dijalankan. Salah satu dari programnya adalah mobil ambulance beserta operasionalnya secara gratis.

Mobil ambulance dapat dimanfaatkan oleh masyarakat kaya ataupun miskin, akan tetapi jika masyarakat ingin infaq bisa diterima oleh BAZNAS, dan akan dibukukan di dalam buku infaq, yang sudah disediakan didalam mobil ambulance. Dari satu sisi, mobil ambulance tersebut dapat menyejahterakan ummat, dan mengurangi beban yang ditanggung masyarakat dalam hal penyewaan transportasi untuk pergi berobat atau mengantar jenazah. Disisi lain, pemanfaatan mobil ambulance belum merata terhadap masyarakat Rembang, dikarenakan dana yang terkumpul belum cukup untuk membelikan mobil ambulance untuk 14 kecamatan yang ada di Rembang.

Dengan demikian, problematika yang muncul terhadap pendayagunaan ZIS untuk operasional ambulance gratis yaitu belum meratanya penyaluran mobil ambulance terhadap masyarakat Rembang. Berkaitan dengan problematika yang ada, maka penulis dalam menyusun karya ilmiah ini ingin menjawab dua pokok masalah, yaitu: bagaimana pendayagunaan ZIS untuk operasional ambulance gratis di BAZNAS Rembang dan apa kendala dan solusi dalam pendayagunaan ZIS untuk operasional ambulance gratis di BAZNAS Rembang. 


\section{Nita Sari}

\section{Pembahasan}

\section{Kajian zakat, infak dan sedekah}

Zakat berarti suci, tumbuh, bertambah, dan berkah. Zakat itu membersihkan (menyucikan) diri seseorang dan hartanya, pahala bertambah, harta tumbuh (berkembang), dan membawa berkat (Hasan, 2006: 15). Sesudah mengeluarkan zakat seseorang telah suci (bersih) dirinya dari penyakit kikir dan tamak. Hartanya juga telah bersih, karena tidak ada lagi hak orang lain pada hartanya. Adapun pengertian zakat menurut pendapat ulama, diantaranya:

1) Mazhab Hanafi mendefinisikan zakat dengan menjadikan hak milik bagian harta tertentu dan harta tertentu untuk orang tertentu yang telah ditentukan oleh Syari' karena Allah (Arifin, 2011: 5).

2) Mazhab Maliki berpendapat bahwa zakat adalah mengeluarkan bagian tertentu dari harta tertentu yang telah mencapai satu nisab bagi orang yang berhak menerimanya, dengan ketentuan harta itu milik sempurna, telah haul, dan bukan merupakan barang tambang (Supadie, 2013: 37).

3) Mazhab Syafi'i mendefinisikan zakat adalah sesuatu yang dikeluarkan dari harta atau jiwa dengan cara tertentu.

4) Mazhab Hanbali mendifinisikan zakat dengan hak yang wajib dalam harta tertentu bagi kelompok tertentu pada waktu tertentu.

5) Ulama kontemporer Yusuf Qardhawi, menjelaskan bahwa zakat adalah sejumlah harta tertentu yang diwajibkan Allah menyerahkan kepada orang-orang yang berhak.

6) Menurut Imam Asy Syarkhasyi al Hanafi dalam kitabnya Al Mabsuth mengatakan bahwa dari segi bahasa zakat adalah tumbuh dan bertambah. 


\section{Pendayagunaan Dana ZIS untuk Operasional ...}

Disebut zakat karena sesungguhnya ia menjadi sebab bertambahnya harta dimana Allah Ta'ala menggantinya di dunia dan pahala di akhirat (Arifin, 2011).

Jika dirumuskan, maka Zakat adalah bagian dari harta yang wajib diberikan oleh setiap muslim yang memenuhi syarat kepada orang-orang tertentu, dengan syarat-syarat tertentu pula. Syarat-syarat tertentu itu adalah nisab, haul, dan kadarnya (Daud Ali, 1988: 39).

Zakat adalah rukun Islam ketiga, yang merupakan pilar agama yang tidak dapat berdiri tanpa pilar ini. Zakat hukumnya wajib 'ain bagi setiap muslim apabila telah memenuhi syarat-syarat yang telah ditentukan oleh syari'at (Kurnia, 2008: 5).

Ayat perintah menunaikan zakat telah dikemukakan dalam Qur'an Surat al- Baqarah ayat 267: “Wahai orang-orang yang beriman, nafkahkanlah (dijalan Allah) sebagian dari hasil usahamu yang baik-baik dan sebagian dari apa yang Kami keluarkan dari bumi untuk kamu dan janganlah kamu memilih yang buruk-buruk lalu kamu menafkahkan daripadanya, padahal kamu sendiri tidak mau mengambilnya melainkan dengan memincingkan mata terhadapnya, dan ketahuilah, bahwa Allah Maha Kaya lagi Maha Terpuji". (QS. Al-Baqarah: 267).

Infaq berasal dari kata anfaqa yang berarti mengeluarkan, membelanjakan (harta atau uang) (Arifin, 2011: 173). Sedangkan infaq menurut pengertian umum adalah shorful mal ilal hajah yang artinya mengatur atau mengeluarkan harta untuk memenuhi keperluan. Yang dimaksud keperluan disini yaitu mengeluarkan harta dalam kebaikan yang diridhoi Allah SWT (Wawan, 2011: 19). Infaq dikeluarkan oleh setiap orang yang beriman baik berpenghasilan rendah, baik disaat sempit ataupun lapang.

Sedekah adalah memberikan sesuatu (sebagian hartanya) dari seorang muslim kepada muslim lainnya yang 


\section{Nita Sari}

membutuhkan tapi tidak terpaut dengan nishab dan haulnya. Sedekah berasal dari kata shadaqa berarti benar. Orang yang suka sedekah adalah orang yang benar pengakuan imannya. Adapun secara terminology syariat sedekah makna aslinya adalah tahqiqi syai'in bisya'i atau menetapkan/menerapkan sesuatu pada sesuatu. Sikapnya sukarela dan tidak terikat pada syarat-syarat tertentu dalam pengeluarannya baik mengenai jumlah, waktu dan kadarnya. Atau pemberian sukarela yang dilakukan oleh seseorang kepada orang lain, terutama kepada orang-orang miskin setiap kesepatan terbuka yang tidak ditentukan baik jenis, jumlah maupun waktunya, sedekah tidak terbatas pada pemberian yang bersifat material saja tetapi juga dapat berupa jasa yang bermanfaat bagi orang lain.

Bahkan senyum yang dilakukan dengan ikhlas untuk menyenangkan orang lain termasuk kategori sedekah. Sedekah mempunyai cakupan yang sangat luas dan digunakan al-Qur'an untuk mencakup segala jenis sumbangan. Sedekah berarti memberi derma, termasuk memberi derma untuk memenuhi hukum dimana kata zakat digunakan dalam al-Qur'an dan sunnah. Zakat juga dapat disebut sedekah karena zakat juga merupakan derma yang diwajibkan sedangkan sedekah adalah sukarela. Zakat dikumpulkan oleh pemerintah sebagai suatu pungutan wajib, sedangkan sedekah adalah lainnya dibayar sukarela (Anam, 2011: 35-36).

\section{Pendayagunaan Zakat, Infaq dan Sedekah}

Pendayagunaan berasal dari kata daya-guna yang berarti kemampuan mendatangkan hasil atau manfaat. Istilah pendayagunaan dalam konteks ini mengandung makna pemberian zakat kepada para mustahiq secara konsumtif maupun produktif dengan tujuan agar mendatangkan manfaat atau hasil (Hasan, 2011: 71). Pendayagunaan zakat, infaq, dan sedekah adalah 
pengupayaan agar harta zakat, infaq dan sedekah mampu mendatangkan hasil bagi penerimanya. Zakat, infaq, dan sedekah merupakan sumber dana yang potensial yang dapat dimanfaatkan untuk meningkatkan kesejahteraan hidup ummat manusia, terutama golongan orang fakir miskin, sehingga mereka bisa hidup layak secara mandiri, dan menggantungkan nasibnya tanpa belas kasihan orang lain. Untuk menghilangkan ketergantungan pada harta orang lain tidak mungkin mustahiq hanya diberi zakat yang bersifat konsumtif saja. Hal itu tidak akan meningkatkan kemandirian tapi akan menambah ketergantungan orang lain (Nawawi, September 2017). Keberhasilan zakat tergantung kepada pendayagunaan dan pemanfaatannya. Walaupun seseorang wajib zakat (muzakki) mengetahui dan mampu memperkirakan jumlah zakat yang akan ia keluarkan, tidak dibenarkan ia meyerahkannya kepada sembarang orang yang ia sukai. Zakat harus diberikan kepada yang berhak (mustahiq) yang sudah ditentukan menurut agama. Penyerahan yang benar adalah melalui Badan Amil Zakat ataupun Lembaga Amil Zakat. Badan Amil Zakat dan Lembaga Amil Zakat mempunyai tugas untuk mengefektifkan pendayagunaannya. Pendayagunaan yang efektif ialah efektif manfaatnya (sesuai dengan tujuan) dan jatuh pada yang berhak (sesuai dengan nas) secara tepat guna (Kemenag RI, 2012: 88).

Keberhasilan pendayagunaan dana ZIS, ditentukan oleh adanya pembagian wilayah kerja antar Badan Amil Zakat Nasional (BAZNAS) dalam memberdayakan masyarakat. Pembagian kerja pendayagunaan zakat bertujuan agar dana zakat dapat diserap oleh berbagai lapisan masyarakat yang membutuhkannya secara maksimal (IMZ, 2012). 


\section{Nita Sari}

\section{Prinsip Pendayagunaan}

Dalam pendayagunaan zakat, ada tiga prinsip yang perlu diperhatikan yaitu:

1) Diberikan kepada delapan asnaf, yaitu fakir, miskin, amil, muallaf, riqab, gharim, sabilillah, dan ibnu sabil.

2) Manfaat Zakat itu dapat diterima dan dirasakan manfaatnya (Depag RI, 2003). Agar dana zakat yang disalurkan itu dapat berdaya guna dan berhasil guna, maka pemanfaatannya harus selektif, diantaranya yaitu:

a) Konsumtif

(1) Konsumtif Tradisional

Zakat dibagikan kepada mustahiq secara langsung untuk kebutuhan konsumsi seharihari, seperti pembagian zakat fitrah berupa beras dan uang kepada fakir miskin setiap idul fithri atau pembagian zakat maal secara langsung oleh para muzakki kepada mustahiq yang sangat membutuhkan karena ketiadaan pangan atau karena mengalami musibah. Pola ini merupakan program jangka pendek dalam mengatasi permasalahan umat.

(2) Konsumtif Kreatif

Zakat yang diwujudkan dalam bentuk barang konsumtif dan digunakan untuk membantu orang miskin dalam mengatasi permasalahan social dan ekonomi yang dihadapinya. Bantuan tersebut antara lain berupa alat-alat sekolah dan beasiswa untuk para pelajar, bantuan sarana ibadah seperti sarung dan mukena, bantuan alat pertanian seperti cangkul untuk petani, gerobak jualan untuk pedagang kecil (Depag RI, 2005). 
Pendayagunaan Dana ZIS untuk Operasional ...

b) Produktif

(1) Produktif Konvensional

Zakat diberikan dalam bentuk barang-barang produktif dimana dengan menggunakan barang-barang tersebut, para mustahiq dapat menciptakan suatu usaha, seperti pemberian bantuan ternak kambing, mesin jahit, dan lainnya.

(2) Produktif Kreatif

Zakat dapat diwujudkan dalam bentuk pemberian modal bergulir baik untuk permodalan proyek sosial seperti membangun sekolah, sarana kesehatan, sebagai modal usaha untuk membantu atau mengembangkan usaha para pedagang dan pengusaha kecil (Depag RI, 2005).

3) Sesuai dengan keperluan mustahiq. (konsumtif atau produktif) (Depag RI, 2005).

\section{Tahapan Pendayagunaan}

Pendayagunaan dapat dilakukan dengan beberapa tahap, diantaranya adalah:

1) Penyaluran Murni

Tahap penyaluran murni umumnya setiap dana yang ada digunakan untuk kegiatan karitatif langsung. Biasanya pada saat dibagikan, dana langsung habis sesuai dengan penyampaian bantuan yang dilakukan. Orientasi tahap penyaluran murni adalah sampainya dana kepada orang yang berhak menerima. Artinya, pada tahap penyaluran ini, yang diutamakan adalah sampainya dana kepada pihak yang berhak menerima.

2) Semi Pendayagunaan 


\section{Nita Sari}

Pada tahap ini, dana yang ada selain digunakan untuk hibah konsumtif, santunan dan kegiatan kariatif juga digunakan untuk kegiatan-kegiatan pengembangan Sumber Daya Manusia (SDM). Tahap semi pendayagunaan inii saat dibagikan, dana juga langsung habis. Orientasi tahap ini adalah selain sampainya dana kepihak yang menerima, juga orientasi manfaat dana (program) bagi penerima dana tersebut.

3) Pendayagunaan

Pendayagunaan merupakan tahap terakhir. Pada tahap ini dana yang ada digunakan untuk kegiatan hibah, baik untuk kegiatan karitas langsung maupun tidak langsung. Pengembangan SDM dan ekonomi. Dana pada tahap pendayagunaan ini tidak langsung habis, karena digunakan untuk kegiatan ekonomi yang secara berkala terus berputar dikalangan pihak yang menerima. Orientasi pada tahap ini adalah perubahan pihak yang menerima setelah mendapatkan bantuan dari badan zakat maupun lembaga zakat.

\section{Pendayagunaan Zakat, Infaq dan Sedekah untuk} Operasional Ambulance Gratis di BAZNAS Rembang

Pendayagunaan berasal dari kata daya-guna yang berarti kemampuan mendatangkan hasil atau manfaat. Zakat, infaq dan sedekah merupakan ibadah dengan cara mengeluarkan harta untuk diberikan kepada seseorang atau lembaga yang mengelola dana ZIS. Pendayagunaan ZIS untuk operasional ambulance gratis yaitu pemanfaatan dana zakat, infaq dan sedekah yang digunakan untuk membeli mobil ambulance beserta operasional secara gratis. Dalam pelaksanaan program ini, BAZNAS Rembang membuat SOP. SOP program mobil ambulance gratis terdapat penjelasan mengenai tujuan ketentuan dasar pemakaian 


\section{Pendayagunaan Dana ZIS untuk Operasional ...}

ambulance, sayarat penggunaan, biaya operasional, dan syarat-syarat pengemudi.

Hasil data yang didapatkan oleh peneliti menjelaskan bahwa, pendayagunaan dana ZIS untuk operasional ambulance gratis termasuk berhasil, meskipun pendistribusiannya belum merata. Hal ini, terbukti dari pengelolaan mobil ambulance disetiap kecamatan sesuai dengan SOP mobil ambulance BAZNAS Rembang. Di dalam SOP dijelaskan, operasional ambulance yang ditanggung oleh BAZNAS Rembang yaitu sebagai berikut:

a) Biaya operasional perawatan, meliputi:

1) Jasa sopir yang sudah ditetapkan oleh pengelola.

2) Bahan bakar, oli, biaya jalan tol dan cuci mobil.

3) Uang makan sopir (dalam hal ini disesuaikan dengan jaraknya)

4) Insiden tak terduga, seperti terkena tilang, kecelakaan kecil misalnya ban bocor.

5) Biaya operasional perawatan ditanggung oleh pengelola Kecamatan dari hasil infaq ambulance.

b) Biaya operasional pemeliharaan, meliputi:

1) Penggantian suku cadang.

2) Perpanjangan Surat Tanda Nomor Kendaraan (STNK).

3) Service

4) Biaya operasional pemeliharaan ditanggung oleh BAZNAS Rembang

c) Biaya perbaikan bila terjadi kecelakaan berat

1) Apabila mengganti suku cadang dengan nilai diatas Rp 5.000.000 ditanggung bersama antara pengelola Kecamatan dan BAZNAS Rembang, adapun prosentasenya bisa dimusyawarahkan. 


\section{Nita Sari}

2) Apabila biaya suku cadang kurang dari Rp 5.000.000 maka ditanggung oleh BAZNAS Rembang.

BAZNAS Rembang telah memberikan layanan kepada masyarakat dari dana ZIS untuk membelikan mobil ambulance beserta operasionalnya. Dari hasil penelitian, pengelola mobil ambulance melaksanakan tugasnya sesuai dengan SOP, dari operasional perawatan yang ditanggung pengelola Kecamatan, biaya operasioanl pemeliharaan, dan biaya perbaikan bila terjadi kecelakaan berat. Sebagaimana data yang juga didapat peneliti bahwa BAZNAS Rembang telah mendistribusikan 5 mobil ambulance. Meskipun 9 Kecamatan belum mendapatkan mobil ambulance, BAZNAS akan berusaha untuk memenuhi kebutuhan tersebut, yang menjadi kendala untuk mendistribusikan mobil kesemua Kecamatan yaitu dana ZIS yang kurang memadai, karena di BAZNAS Rembang dana ZIS tidak hanya berpusat untuk program ambulance gratis.

Dapat dikatakan bahwa BAZNAS Rembang mendayagunakan zakat, infaq dan sedekah untuk ambulance gratis dilaksanakan secara bertahap. Program ambulance gratis sangat membantu masyarakat atau mustahiq dalam membantu pengantaran jenazah kepemakan atau mengantar orang sakit ke Rumah Sakit, dengan adanya program ini masyarakat atau mustahiq merasa senang karena dapat mengurangi beban biaya transportasi. Dengan demikian, dapat dikatakan bahwa pendayagunaan zakat, infaq dan sedekah untuk operasional ambulance gratis di BAZNAS Rembang termasuk berhasil, meskipun terkadang ada kendala pada saat ambulance beroperasi. 


\section{Kendala dan Solusi dalam Pendayagunaan Zakat, Infaq dan Sedekah untuk Operasional Ambulance Gratis di BAZNAS Rembang}

Kendala dalam pelaksanaan program tentu akan dihadapi oleh lembaga. Jika dalam program kerja ada kendala tentu ada solusi yang harus diatasi. Dari data yang ada, dalam melaksanakan program operasional ambulance gratis ada beberapa kendala yang dihadapi setiap koordinator kecamatan.

Hasil wawancara dan observasi peneliti yang menjadi penghambat berjalannya program ambulance gratis tidak terlalu banyak, dan hambatan-hambatan tersebut masih bisa diatasi oleh BAZNAS Rembang. Akan tetapi, dalam mengatasi masalah-masalah dalam pelaksanaan program ambulance gratis ini membutuhkan waktu yang tidak sebentar. Artinya, BAZNAS Rembang mampu melakanakan solusi dari hambatan-hambatan tersebut butuh waktu yang lama. Pada saat ini yang menjadi kendala bagi BAZNAS Rembang, yaitu:

a. Belum meratanya pendistribusian mobil ambulance

b. Pada saat terjadi kecelakaan BAZNAS Rembang tidak bertanggung jawab sepenuhnya.

c. Kurangnya kesadaran masyarakat untuk membayar zakatnya di Lembaga. Padahal, jika masyarakat Rembang sadar akan zakat yang dibayarkan ke lembaga, akan berdampak positif bagi masyarakat Rembang. Jika semua masyarakat Rembang menyalurkan ZIS nya ke BAZNAS, maka BAZNAS akan mengelola dana ZIS secara profesioanal dengan tujuan mensejahterakan mustahiq dan dapat mengentaskan kemiskinan di Kabupaten Rembang. 


\section{Nita Sari}

BAZNAS Rembang dalam menjalankan program ambulance gratis tentu ada kendala untuk mencapai suatu tujuan. Untuk menghadapi kendala-kendala yang ada, tentu ada solusi untuk menyelesaikannya. Adapun solusi penulis dalam menghadapi kendala yang ada adalah sebagai berikut:

a. Agar pendistribusian mobil ambulance merata di 14 Kecamatan Rembang, maka BAZNAS Rembang harus meningkatkan fundraising ZIS. Pada saat ini donatur BAZNAS yaitu PNS se Kabupaten Rembang, dan masyarakat yang mau menyalurkan dana ZISnya ke BAZNAS Rembang. Ada satu moment untuk bisa dijadikan pengumpulan dana infaq dan sedekah untuk BAZNAS Rembang. Pada saat pemberangkatan haji, mobil ambulance yang ada di kecamatan Rembang, digunakan untuk mengiringi bus jamaah calon haji sampai ke bandara. Dengan adanya moment seperti ini BAZNAS dapat bekerja sama dengan penyuluh KEMENAG Rembang, untuk memberi tahu kepada calon jamaah haji, jikalau mau infaq atau sedekah bisa di kantor KEMENAG yang nantinya akan dibukukan di kantor BAZNAS Rembang.

b. Sebenarnya di dalam SOP ambulance gratis sudah dijelaskan, bahwa jika terjadi kecelakaan BAZNAS Rembang hanya menanggung kerusakan mobil. Jadi, tidak salahnya BAZNAS Rembang jika terjadi kecelakaan, BAZNAS Rembang hanya bertanggung jawab dikerusakan mobil ambulance.

c. Agar masyarakat Rembang sadar akan zakat dan membayar zakatnya di BAZNAS Rembang, maka BAZNAS Rembang harus sering melaksanakan sosialisasi. Jika sosialisasi dilaksanakan terus 


\section{Pendayagunaan Dana ZIS untuk Operasional ...}

menerus, maka masyarakat akan mengenal BAZNAS Rembang dan memahami teori zakat, infaq dan sedekah.

\section{Simpulan}

Berdasarkan kajian di atas, maka dapat disimpulkan bahwa pendayagunaan zakat, infaq dan sedekah untuk operasional ambulance gratis adalah dana ZIS yang digunakan untuk mobil ambulance beserta operasionalnya secara gratis dan mendatangkan manfaat bagi penerima layanan tersebut. Bentuk pendayagunaan ZIS yang diberikan oleh BAZNAS Rembang untuk operasional ambulance gratis diantaranya adalah jasa sopir yang sudah ditetapkan oleh pengelola, bahan bakar, oli, biaya jalan tol dan cuci mobil, uang makan sopir (dalam hal ini disesuaikan dengan jaraknya), insiden tak terduga, seperti terkena tilang, kecelakaan kecil misalnya ban bocor, penggantian suku cadang, perpanjangan Surat Tanda Nomor Kendaraan (STNK), service, serta biaya perbaikan bila terjadi kecelakaan berat.

Kerja sama yang dilakukan oleh BAZNAS Rembang dalam program ini adalah dengan pihak kecamatan. Jadi, jika masyarakat ingin memanfaatkan mobil ambulance secara gratis, dapat menghubungi pihak koordinator program di setiap kecamatan. Pendayagunaan ZIS untuk operasional ambulance gratis termasuk pendayagunaan konsumtif kreatif. Program ambulance beserta operasional ambulance gratis sangat bermanfaat dan membantu masyarakat fakir, miskin dalam mengantar orang sakit ke rumah sakit dan mengantar jenazah ke pemakaman.

Dalam menjalankan program tentu ada kendala untuk mencapai suatu tujuan. Adapun kendala yang dihadapi oleh pengelola mobil ambulance adalah: 


\section{Nita Sari}

a. Jumlah mobil ambulance yang terbatas untuk melayani masyarakat Rembang, sehingga jika terjadi waktu yang bersamaan dalam melayani masyarakat, BAZNAS harus memilih salah satunya.

b. Belum meratanya pendistribusian mobil ambulance di 14 Kecamatan Rembang

c. Layanan kontak mobil ambulance gratis yang belum familier di kalangan masyarakat.

d. BAZNAS Rembang belum bisa bertanggung jawab sepenuhnya, jika mobil ambulance terjadi kecelakaan.

Sedangkan solusi untuk menghadapi kendala yang ada dalam program operasional ambulance gratis ini adalah:

a. Agar pendistribusian mobil ambulance merata, BAZNAS Rembang harus meningkatkan fundraising dana ZIS.

b. Agar kontak layanan mobil ambulance dapat familier di masyarakat, koordinator setiap kecamatan harus sering-sering mensosialisasikan program ambulance beserta operasionalnya secara gratis.

\section{Daftar Pustaka}

Ali Daud Muhammad, Sistem Ekonomi Islam Zakat dan Wakaf, UI-Press, Jakarta, 1988.

Arifin Gus, Zakat, Infaq, Sedekah (Dalil-Dalil dan Keutamaan), Gramedia, Jakarta, 2011.

Bungin Burhan, Analisis Data Penelitian Kualitatif, Raja Grafindo Persada, Jakarta, 2005. 


\section{Pendayagunaan Dana ZIS untuk Operasional ...}

Departemen Agama RI, Manajemen Pengelolaan Zakat, Direktorat Pengembangan Zakat dan Wakaf, Jakarta, 2005.

Departemen Agama RI, Pedoman Pengelolaan Zakat, Direktorat Pengembangan Zakat dan Wakaf, Jakarta, 2003.

Departemen Agama RI, Profil Direktorat Pemberdayaan Zakat, Direktorat Pemberdayaan Zakat, Jakarta, 2006.

Hasan Ali M., Zakat dan Infaq (Salah Satu Solusi Mengatasi Problema Sosial di Indonesia), Prenadamedia Group, Jakarta, 2006.

IMZ, Membangun Peradaban Zakat Indonesia, Indonesia Magnificence of Zakat, Ciputat, 2012.

Kementerian Agama RI, Panduan Organisasi Pengelola Zakat, Direktorat Pemberdayaan Zakat, Jakarta, 2012.

Kurde Arfawie Nukthoh, Memungut Zakat \& Infaq Profesi, Pustaka Pelajar, Yogyakarta, 2005.

Nawawi Sofwan, Zaman-Rosulullah-Zakat-Untuk-Atasi Kesulitan Ekonomi, www.pkpu.or.id/news/, diakses pada 13 September 2017.

Sugiyono, Metode Penelitian Pendidikan (Pendekatan Kuantitatif, Kualitati, dan RED), Bandung, 2014.

Supadie Ahmad Didiek, Sistem Lembaga Keuangan Ekonomi Syariah Dalam Pemberdayaan Ekonomi Rakyat, Pustaka Rizki Putra, Semarang, 2013.

Wibisono Yusuf, Mengelola Zakat Indonesia, Prenadamedia Group, Jakarta, 2015. 